\title{
PENGARUH KUALITAS PELAYANAN DAN KUALITAS PRODUK TERHADAP KEPUASAN PELANGGAN PADA PT ANEKA TATA NIAGA
}

\author{
Hermanto $^{1}$, Nora Pitri Nainggolan ${ }^{2}$ \\ ${ }^{1}$ Mahasiswa Program Studi Manajemen, Universitas Putera Batam \\ ${ }^{2}$ Dosen Program Studi Manajemen, Universitas Putera Batam \\ e-mail :pb160910057@upbatam.ac.id
}

\begin{abstract}
The purpose of this study was to determine the effect of service quality and product quality on customer satisfaction at PT Aneka Tata Niaga using slovin sampling technique with a margin of error of 5\% of 155 customers so as to produce 112 respondents who are customers at PT Aneka Tata Niaga. Data collection methods are questionnaires. Data quality test in this study uses the validity and reliability test, the classic assumption test and the influence test in this study using multiple linear regression analysis and coefficient of determination analysis $(R 2)$, while the hypothesis testing in this study uses ( $t$ test) and ( $F$ test) by using SPSS version 23 software program. the results show that service quality has a partially significant effect on customer satisfaction and product quality has a partially significant effect on customer satisfaction, and service quality and product quality together have a significant simultaneous effect on customer satisfaction at PT Various Commerce.
\end{abstract}

Keywords: Service Quality, Product Quality, Customer Satisfaction

\begin{tabular}{cl}
\hline bersaing dalam kompetisi yang & berkembangnya teknologi, infomasi, \\
sangat ketatini. & komunikasi, yang berdampak \\
PT Aneka Tata Niaga adalah & terhadap kecepatan para pelanggan \\
perusahaan lokal yang di dirikan pada & mendapatkan informasi terhadap \\
tahun 2010 yang berlokasi di komplek & suatu produk ataupun jasa. Ini \\
Graha Permata Indah blok. A No. 7 Batu & merupakan sebuah tantangan bagi \\
Ampar, Kota Batam dengan aktivitas & perusahaan - perusahaan yang \\
utama yaitu mengimpor produk dan & bergerak dibidang perdagangan \\
menjual produknya ke pasar, & barang atau jasa, terutama pada \\
PENDAHULUAN & bagian tim pemasaran dalam hal \\
Pada era bisnis saat ini, persaingan & mendalami apa yang di butuhkan oleh \\
dunia bisnis semakin ketat.Persaingan & pelanggan, strategi apa yang di \\
global sudah tidak dapat lagi & jalankan oleh pesaing, memberikan \\
terhindarkan oleh perusahaan - & pelayanan yang baik, dapat \\
perusahaan yang ada terutama di & memetakan lokasi penjualan, \\
Indonesia ini. Semakin & a
\end{tabular}


memiliki komitmen sebagai pemasar yang baik, serta memiliki teknologi yang canggih. Oleh karena itu, bagian pemararan sangat penting peranannya dalam sebuah perusahaan dan bagian pemasaran adalah ujung tombak dalam suatu perusahaan Memuaskan pelanggan adalah keinginan dari setiap perusahaan. Selain penting bagi kelangsungan hidup perusahaan, hal yang penting dalam memuaskan pelanggan adalah dapat meningkatkan keunggulan dalam persaingan.Dalam hal inilah setiap perusahaan perlu memperhatikan faktor- faktor yang penting seperti kualitas pelayanan dan kualitas produk agar dapat tetap hotel, cafe dan perusahaan lain. Beberapa produk yang di di distribusikan oleh PT Aneka Tata Niaga adalah daging - daging frozen dari luar negri maupun dari dalam negri. Adapun perusahaan lain yang menjual produk yang sama antara lain : Dewi Niaga, Dewi Kartika, Sukses Niaga Lestari, Minang Jaya dan Martindo frozen food.

diatas menunjukkan bahwa pada tahun 2016 jumlah komplain terhadap kualitas pelayanan sebanyak 70 , dan pada tahun 2017 meningkat sebesar 83, dan pada tahun 2018 jumlah komplain meningkat sebesar 95. Hal ini menunjukan bahwa kualitas pelayanan semakin menurun sehingga dapat mengakibatkan pelanggan kurang puas terhadap pelayanan dan pindah ke kompetitor lain. Komplain pada kualitas pelayanan sering terjadi karena pengantaran barang kepada pelanggan sering terlambat sehingga pelanggan yang ingin berjualan terpaksa harus mengunggu, pelanggan sering keberatan untuk waktu order yang di batasi sampai pada jam 4 sore jika barang yang di order untuk pengiriman subuh sedangkan pada kompetitor lain tidak di batasi waktu order untuk pengiriman subuh sehingga pelanggan tidak mesti buru- buru dalam mengecek persediaan mereka dan melakukan order barang, barang yang telah di terima dan telah ditanda tangan surat jalannya tidak dapat di retur kembali maupun barang yang di terima kualitasnya kurang bagus, persediaan barang sering tidak mencukupi permintaan pelanggan sehingga apa yang di butuhkan pelanggan sering tidak dapat di penuhi, seringkali terjadi keterlambatan informasi dari pihak perusahaan kepada pelanggan jika persediaan barang sudah kosong sehingga pelanggan sering kali sudah order tetapi barangnya tidak ada, dan juga keterlambatan memberi informasi jika ada kenaikan harga maupun turun harga. dan pada hari minggu PT Aneka Tata Niaga libur sedangkan kompetitor tidak libur sedangkan pelanggan membutuhkan barang setiap hari untuk dijual karena PT Aneka Tata Niaga libur pelanggan tidak bisa memesan barang pada hari minggu tersebut dan terpaksa memesan kepada kompetitor lain.

diatas dapat di lihat bahwa jumlah reject pada tahun 2016 terhadap kualitas produk sebesar 88, tahun 
2017 jumlah reject terhadap kualitas produk sebesar 80, pada tahun 2018 jumlah reject terhadap kualitas produk 108. Data ini menunjukkan bahwa tingkat produk yang di reject semakin meningkat sehingga menujukkan kualitas produknya semakin menurun. Hal ini dapat di sebabkan oleh barang yang dikirim kemasannya rusak, barang yang dikirim sudah sedikit cair sehingga kualitas pada dagingnya menurun yang diakibatkan karena kendaraan yang di gunakan untuk mengirim barang tidak memiliki pendingin.

Penjualan PT Aneka Tata Niaga juga mengalami fluktuasi dan di tahun 2018 mengalami penurunan Berdasarkan data diatas menunjukkan bahwa penjualan pada PT Aneka Tata Niaga pada tahun 2016 penjualan total sebesar 104.936, dan pada tahun 2017 mengalami kenaikan hingga 107.106, kemudian pada tahun 2018 mengalami penurunan hingga penjualan total hanya mencapai 101.754. hal ini dikarenakan menurunnya tingkat kepuasan pelanggan yang sering kali terjadi karena banyaknya komplain dari pelanggan kepada perusahaan, seperti pelanggan yang tidak puas atas produk yang di beli seperti barang yang dikirim sudah mencair, barang tidak sesuai dengan harapan yang diinginkian, pelayanan yang kurang seperti keterlambatan dalam informasi stok yang sudah menipis sehingga pelanggan tidak dapat menyimpan persediaan untuk dijual ketika barang sudah kosong, keterlambatan dalam pengiriman barang, informasi perubahaan harga yang terlambat diberitahukan kepada pelanggan hal -hal ini juga dapat mengakibatkan menurunnya kepuasan pelanggan yang mengakibatkan pelanggan beralih kepesaing lain sehingga penjualan pada perusahaan juga dapat mengalami penurunan.

Dalam memenuhi kepuasan pelanggan faktor yang perlu di perhatikan oleh adalah kualitas pelayanan dan kualitas produk.

Komplain pada kualitas pelayanan sering terjadi karena pengantaran barang kepada pelanggan sering terlambat sehingga pelanggan yang ingin berjualan terpaksa harus mengunggu, pelanggan sering keberatan untuk waktu order yang di batasi sampai pada jam 4 sore jika barang yang di order untuk pengiriman subuh sedangkan pada kompetitor lain tidak di batasi waktu order untuk pengiriman subuh sehingga pelanggan tidak mesti buruburu dalam mengecek persediaan mereka dan melakukan order barang, barang yang telah di terima dan telah ditanda tangan surat jalannya tidak dapat di retur kembali maupun barang yang di terima kualitasnya kurang bagus, persediaan barang sering tidak mencukupi permintaan pelanggan sehingga apa yang di butuhkan pelanggan sering tidak dapat di penuhi, seringkali terjadi keterlambatan informasi dari pihak perusahaan kepada pelanggan jika persediaan barang sudah kosong 
sehingga pelanggan sering kali sudah order tetapi barangnya tidak ada, dan juga keterlambatan memberi informasi jika ada kenaikan harga maupun turun harga. dan pada hari minggu PT Aneka Tata Niaga libur sedangkan kompetitor tidak libur sedangkan pelanggan membutuhkan barang setiap hari untuk dijual karena PT Aneka Tata Niaga libur pelanggan tidak bisa memesan barang pada hari minggu tersebut dan terpaksa memesan kepada kompetitor lain.

Komplain yang sering terjadi pada kualitas produk seperti barang yang dikirim kemasannya rusak, barang yang dikirim sudah sedikit cair sehingga kualitas pada dagingnya menurun yang diakibatkan karena kendaraan yang di gunakan untuk mengirim barang tidak memiliki pendingin. Permasalahan diatas dapat mengakibatkan pelanggan merasa tidak puas terhadap apa yang diberikan oleh perusahaan kepada pelanggan dan berpindah kepada kompetitor lain. Berdasarkan penjabaran permasalahan diatas, adapun tujuan dari penulisan ini adalah untuk mengetahui pengaruh kualitas pelayanan dan kualitas produk terhadap kepuasan pelanggan.Penelitian ini hanya membahas tentang pengaruh kualitas pelayanan dan kualitas produk terhadap kepuasan pelanggan.

\section{KAJIAN TEORI \\ Kualitas Pelayanan}

Kualitas pelayanan merupakan suatu perbandingan yang menjadi ukurang penting dari suatu pelayanan yang diberikan ataupun yang diinginkan pelanggan.(Gunartik \& Nainggolan, 2019: 29).

Indikator kualitas pelayanan menurut (Aswad, Realize, \& Wangdra, 2019:59). Adalah sebagai berikut:

1. Realibilitas (Realibility)

Seberapa besar pelayanan yang diberikan dapat diandalkan oleh orang yang membutuhkan.

2. Daya tanggap (responsiveness)

Secepat apa daya tanggap dari orang yang memberikan pelayanan terhadap kebutuhan.

3. Jaminan (assurance) Jaminan apa yang dapat diberikan kepada penerima pelayanan.

4. Empati (empathy) Bagaimana kita bisa ikut serta dalam merasakan apa yang dirasakan oleh orang-orang

5. Bukti fisik (tangibles)

Pelayanan yang menunjukkan perlunya tampak wujud agar dapat diketahui keasliannya.

\section{Kualitas Produk}

Kualitas produk adalah kombinasi dari karakteristik produk yang berasal dari pemasaran, desain, produksi dan layanan, membuat produk cocok untuk memuaskan konsumen atau harapan mereka.(Meisara, 2019:86). Indikator kualitas produk menurut (Widyastuti, 2017:236). Sebagai berikut:

1. Kinerja (Performance)

Kinerja dari produk tentu menjadi sebuah alat ukur tersendiri bagi pembeli untuk mempertimbangkan 
apakah kedepannya akan membeli produk tersebut kembali.

2. Ciri-ciri atau keistimewaan tambahan (Features)

Sebelum membeli suatu barang seseorang pasti menginginkan sesuatu yang berbeda dari produk sejenisnya.

3. Kesesuaian dengan spesifikasi (Conformace to Spesification)

Pada saat membeli suatu produk, tentu ada spesifikasi tertentu yang ditawarkan baik melalui bungkusan produk tersebut maupun tenaga penjualan informasi tersebut disampaikan.

4. Keandalan (Realibility)

Seberapa besar produk yang dibeli oleh pembeli dapat diandalkan oleh orang yang membutuhkan.

5. Daya tahan (Durability)

Secara umum orang-orang lebih menyukai produk yang memiliki daya tahan yang lama.

6. Estetika (Easthetica)

Sebuah produk yang memiliki keindahan kemasan maupun produk itu sendiri tentu memiliki nilai tambah untuk menarik pembeli.

7. Kualitas yang dipersiapkan (Perceived Quality)

Produk dengan kualitas yang bagaimanakah yang disiapkan oleh orang yang memproduksi agar dapat menarik perhatian dari pembeli.

8. Kemampuan memperbaiki (Service ability)

Bila produk rusak apakah terdapat garansi atau mendapatkan pelayanan jasa lanjutan seperti terdapat gerai resmi yang dapat memperbaikinya.

\section{Kepuasan Pelanggan}

Kepuasan pelanggan adalah kebahagiaan seorang individu setelah kinerja berusaha untuk mencerminkan harapan.(Sholeha, Djaja, \& Widodo, 2018:18).

Ada enam indikator kepuasan pelanggan menurut (Widyastuti, 2017:235) antara lain sebagai berikut

1. Kepuasan pelanggan keseluruhan Untuk kepuasan tidak boleh hanya sebagian dari pelanggan dari perusahaan, diharuskan untuk keseluruhan bila hanya sebagian maka dapat dipastikan terdapat masalah.

2. Penilaian pelanggan

Setiap pelanggan tentu mengalami hal dan masalah yang berbeda dengan yang lainnya sehingga juga memberikan penilaian yang berbeda oleh karena itu wajib memberikan setiap pelanggan kebebasan untuk menilai sesuai dengan kondisi dan fakta yang ada.

3. Konfirmasi harapan

Sebagai seorang penjual tentu harus ada lakukan berbagai komunikasi termasuk memberikan konfirmasi kembali atas pembelian yang dilakukan oleh pembeli dengan demikian pembeli akan lebih merasa nyaman.

4. Minat pembelian ulang 
Bila seseorang mengalami puas atas pembelian sebelumnya maka akan dipastikan pembelian ulang dari orang tersebut akan terjadi.

5. Kesediaan untuk merekomendasi Setelah seseorang tersebut merasakan puas tentu akan merekomendasikan kepada sanak saudaranya untuk melakukan pembelian kepada kita.

6. Ketidakpuasan pelanggan

Untuk menyampaikan ketidakpuasan, pelanggan ada beberapa macam cara untuk melakukan penyampaian seperti memberi kritik dan saran, melampiaskan emosi ditempat bahkan tidak akan melakukan pembelian ulang kemudian menyebar luaskan berita mengenai ketidakpuasannya yang berakhir cukup tidak baik bagi kita selaku penyedia barang dan jasa.

\section{Kerangka Pemikiran}

Berikut adalah gambar dari kerangka pemikiran penelitian ini.

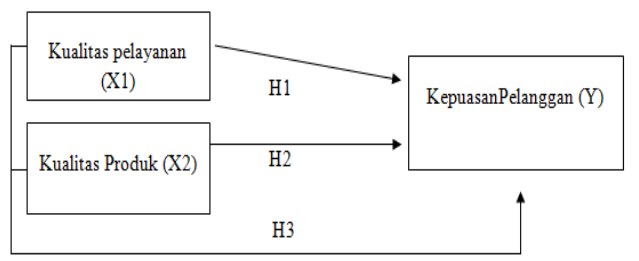

Gambar 1.Kerangka Pemikiran

\section{METODE PENELITIAN Desain Penelitian}

Desain penelitian kausalitas adalah rencana penelitian yang dirancang untuk mempelajari kemungkinan timbal - balik antar variabel.(Sanusi, 2017: 14).

\section{Populasi}

Populasi adalah kombinasi yang menarik bagi para peneliti, karena semua elemen peristiwa, objek, atau bentuk yang serupa dengan karakteristik yang sama dianggap sebagai semesta penelitian, (Isfahila, Fatimah, \& S, 2018: 218)

\section{Sampel}

Sampel adalah adalah jumlah dan karakteristik yang dimiliki oleh populasi tersebut (Rasyid, 2017: 231).Dengan ini peneliti menggunakan slovin sampling untuk menentukan berapa banyak sampel yang akan di ambil dari 155 pelanggan dengan margin errornya $5 \%$. Berdasarkan perhitungan menggunakan slovin sampling, jumlah sampel yang akan dipakai sebanyak 112.31 responden atau dibulatkan menjadi 112 orang responden.

\section{Teknik pengumpulan data}

Metode yang dipakaiuntuk mengumpulkan data yaitu dengan kuesioner.

\section{HASIL DAN PEMBAHASAN Hasil Uji Validitas}

Dalam uji ini pearson yang akan digunakan sebagai analisis dan 0,05 sebagai tingkat signifikannya serta $r$ tabel diperoleh nilai senilai 0,185 yang diuji dengan uji dua arah dan jumlah data (n) sebanyak 112. Hasil 
uji kolerasi semua variabel yang menunjukkan hasil $r$ hitung lebih tinggi dibandingkan $r$ tabel sehingga dapat disimpulkan semua variabel penelitan valid.

\section{Hasil Uji Reliabilitas}

Hasil uji reliabilitas pada variabel kualitas pelayanan diperoleh Cronbatch's Alpha sebesar 0.521, kualitas produk sebesar 0.787 dan kepuasan pelanggan sebesar 0,247 yang menunjukkan bahwa Cronbatch's Alpha lebih besar daripada rtabel 0.185 yang artinya variabel pada penelitian ini reliable.

\section{Hasil Uji Asumsi Klasik} Hasil Uji Normalitas

Pada penelitian ini Uji normalitas dapat dilakukan dengan uji kolmogorov- smirnov yang hasilnya dapat dilihat pada tabel 1 di bawah ini.

Tabel 1 Hasil uji kolmogorov-smirnov

One-Sample Kolmogorov-Smirnov Test

\begin{tabular}{llr}
\hline & & $\begin{array}{c}\text { Unstandardized } \\
\text { Residual }\end{array}$ \\
\hline $\mathrm{N}$ & Mean & 112 \\
Normal Parameters & Sto & .0000000 \\
& Std. Deviation & 2.82646456 \\
Most Extreme Differences & Absolute & .059 \\
& Positive & .059 \\
Test Statistic & Negative & -.048 \\
Asymp. Sig. (2-tailed) & & .059 \\
& & $.200^{c, d}$ \\
\hline
\end{tabular}

Berdasarkan tabel diatas dapat diketahui bahwa nilai probability sig (2 tailed) variabel kualitas pelayanan, kualitas produk dan kepuasan pelanggan sebesar $0,200>0,05$ sehingga dapat menyatakan bahwa data yang diuji berdistribusi normal.

\section{Hasil Uji Multikolinearitas}

Uji Variance Inflation Factor (VIF) digunakan untuk mengetahui apakah terjadinya multikolinearitas antara variabel bebas atau independent variable. (Sulaeman, 2018: 137)

Tabel 2 Hasil Multikolinearitas

\section{Coefficients $^{a}$}




\begin{tabular}{lll}
\hline & \multicolumn{3}{c}{ Collinearity Statistics } \\
Model & Tolerance & VIF \\
\hline $1 \quad$ (Constant) & & \\
Kualitas pelayanan $(X 1)$ & .976 & 1.024 \\
Kualitas produk (X2) & .976 & 1.024 \\
\hline
\end{tabular}

Berdasarkan Tabel 4.17 diatas, dapat dilihat bahwa nilai Variance Inflation Factor (VIF) dari masing-masing variabel Kualitas Pelayanan (X1) dan Kualitas Produk (X2) sebesar 1,024 < 10, dan tolerance value 0,976>0,10, dengan demikian dapat disimpulkan tidak terjadi multikolinearitas.

\section{Hasil Uji Heteroskedastisitas}

Gambar 2 Hasil Uji Heteroskedastisitas

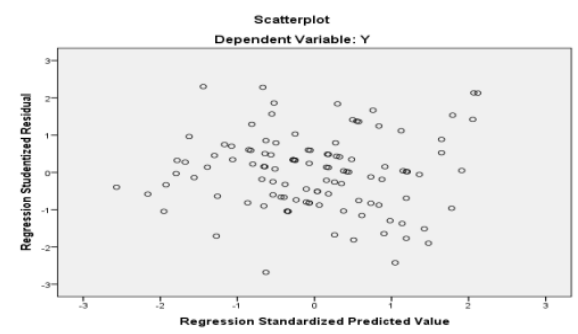

Pada Gambar 2, kita dapat melihat bahwa titik-titik ini didistribusikan dan didistribusikan secara kontinu di atas dan di bawah sumbu 0 dan Y. Dengan ini kita dapat menyimpulkan bahwa tidak ada kejadian heteroskedastisitas.

\section{Hasil Uji Pengaruh}

\section{Hasil Analisis Liniear Berganda}

Dalam analisis ini didapatkan dari hasil penelitian bahwa variabel independen yaitu kualitas pelayanan (X1) dan kualitas produk (X2) terhadap variabel dependen yaitu kepuasan pelanggan (Y). Dengan menggunakan metode analisis regresi linear berganda, maka hasil penelitian yang diperoleh adalah:

Tabel 3Hasil Uji Regresi Liniear Berganda

Coefficients $^{a}$

\begin{tabular}{|c|c|c|c|c|c|}
\hline \multirow[b]{2}{*}{ Model } & \multicolumn{2}{|c|}{$\begin{array}{l}\text { Unstandardized } \\
\text { Coefficients }\end{array}$} & \multirow{2}{*}{$\begin{array}{c}\text { Standardized } \\
\text { Coefficients } \\
\text { Beta } \\
\end{array}$} & \multirow[b]{2}{*}{$t$} & \multirow[b]{2}{*}{ Sig. } \\
\hline & $\mathrm{B}$ & Std. Error & & & \\
\hline (Constant) & 13.111 & 2.984 & & 4.394 & 0 \\
\hline $\mathrm{X} 1$ & 0.185 & 0.067 & 0.243 & 2.752 & 0.007 \\
\hline
\end{tabular}


Berdasarkan hasil pengolahan data pada Tabel 4.18 dapat diperoleh persamaan regresi sebagai berikut.

$$
Y=13.111+0,185 X_{1}+0.169 X_{2}
$$

\section{Hasil Uji Koefisien Determinasi $\left(\mathbf{R}^{2}\right)$}

Untuk mengetahui besarnya kemampuan variabel bebas sacara bersamaan berpengaruh terhadap

Tabel 4 Hasil Uji Koefisien Determinasi $\left(\mathrm{R}^{2}\right)$ Model Summary ${ }^{b}$

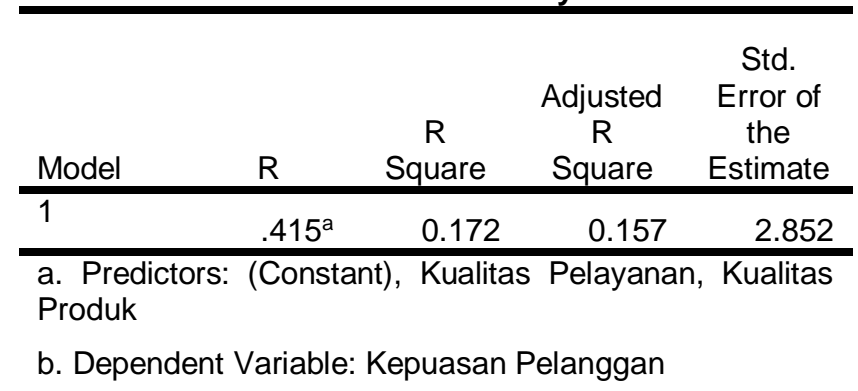

Berdasarkan tabel 4.19 diatas dapat disimpulkan bahwa R Square sebesar 0,172 yang artinya kualitas pelayanan dan kualitas produk berpengaruh sebesar $17,2 \%$ terhadap kepuasan pelanggan.

\section{Hasil Uji Hipotetis} Hasil Uji partial (t)

Uji t digunakan untuk menguji hipotesis secara parsial guna variabel terikat merupakan tujuan dari analisis koefisien determinasi $\left(\mathrm{R}^{2}\right)$. 


\section{Coefficients $^{\mathrm{a}}$}

\begin{tabular}{|c|c|c|c|c|c|c|}
\hline & \multirow[t]{2}{*}{ Model } & \multicolumn{2}{|c|}{$\begin{array}{l}\text { Unstandardized } \\
\text { Coefficients }\end{array}$} & \multirow{2}{*}{$\begin{array}{c}\text { Standardized } \\
\text { Coefficients } \\
\text { Beta }\end{array}$} & \multirow[t]{2}{*}{$\mathbf{t}$} & \multirow{2}{*}{ Sig. } \\
\hline & & B & $\begin{array}{l}\text { Std. } \\
\text { Error }\end{array}$ & & & \\
\hline \multirow{3}{*}{1} & (Constant) & 13.111 & 2.984 & & 4.394 & .000 \\
\hline & $\begin{array}{c}\text { Kualitas pelayanan } \\
(\mathrm{X} 1)\end{array}$ & .185 & .067 & .243 & 2.752 & .007 \\
\hline & Kualitas Produk (X2) & .169 & .049 & .301 & 3.411 & .001 \\
\hline
\end{tabular}

a. Dependent Variable : Kepuasan Pelanggan (Y)

1. Pengaruh Kualitas Pelayanan (X1) terhadap Kepuasan pelanggan (Y) $t_{\text {hitung }}(4,394)>t_{\text {tabel }}(1,981)$ dan nilai signifikansi $=0,007<0,05$ maka Ho ditolak dan Ha diterima. Jadi, kualitas pelayanan (X1) berpengaruh signifikan secara parsial terhadap variabel kepuasan pelanggan (Y).

2. Pengaruh kualitas produk (X2) terhadap kepuasan pelaggan ( $\mathrm{Y}) \mathrm{t}_{\text {hitung }}$ $(3,411)>t_{\text {tabel }}(1,981)$ dan nilai signifikansi $=0,001<0,05$ maka Ho ditolak dan $\mathrm{Ha}$ diterima. Jadi, variabel kualitas produk (X2) berpengaruh signifikan secara parsial terhadap variabel kepuasan pelanggan (Y).

\section{Hasil Uji Simultan (Uji F)}

Uji $F$ merupakan pengujian terhadap koefisien regresi secara bersama-sama yaitu pengaruh dari seluruh variabel independen (X) terhadap variabel dependen (Y), (Edwar M. Nur, 2018: 12).

Tabel 6 Uji Simultan (Uji F)

ANOVA $^{\mathrm{a}}$

\begin{tabular}{|c|c|c|c|c|c|c|}
\hline Mode & & $\begin{array}{l}\text { Sum of } \\
\text { Squares }\end{array}$ & df & $\begin{array}{c}\text { Mean } \\
\text { Square }\end{array}$ & $F$ & Sig. \\
\hline \multirow[t]{2}{*}{1} & Regression & 184.152 & 2 & 92.076 & 11.318 & $.000^{b}$ \\
\hline & $\begin{array}{l}\text { Residual } \\
\text { Total }\end{array}$ & $\begin{array}{r}886.768 \\
1070.920\end{array}$ & $\begin{array}{l}109 \\
111\end{array}$ & 8.135 & & \\
\hline
\end{tabular}

a. Dependent Variable: Kepuasan Pelanggan

b. Predictors: (Constant), Kualitas Produk, Kualitas Pelayanan 
Berdasarkan tabel diatas, diperoleh $F_{\text {hitung }}(11,318)>F_{\text {tabel }}(3,08)$ dan nilai signifikansi $=0,000<0,05$ maka Ho ditolak dan Ha diterima, dengan ditolaknya $\mathrm{HO}$ dan di terimana $\mathrm{Ha}$ dapat disimpulkan bahwa kualitas pelayanan (X1) dan kualitas produk (X2) bersama sama berpengaruh signifikan secara simultan terhadap kepuasan pelanggan (Y).

\section{PEMBAHASAN}

\section{Pengaruh Kualitas Pelayanan} Terhadap Kepuasan Pelanggan

Hasil penelitian ini telah diperoleh bahwa terdapat pengaruh kualitas pelayanan terhadap kepuasan pelanggan PT Aneka Tata Niaga. Melalui hasil perhitungan yang telah dilakukan diperoleh nilai $t_{\text {hitung }}$ $(4,394)>t_{\text {tabel }} \quad(1,981)$ dan nilai signifikansi $=0,007<0,05$ maka Ho ditolak dan Ha diterima.

\section{Pengaruh Kualitas Produk Terhadap Kepuasan pelanggan}

Hasil penelitian ini telah membuktikan terdapat pengaruh kualitas produk terhadap kepuasan pelanggan. Melalui hasil perhitungan yang telah dilakukan yang diperoleh $t_{\text {hitung }}(3,411)>t_{\text {tabel }}(1,981)$ dan nilai signifikansi $=0,001<0,05$ maka Ho ditolak dan Ha diterima.

\section{Kualitas Pelayanan dan Kualitas Produk terhadap Kepuasan Pelanggan}

Hasil penelitian ini telah membuktikan terdapat pengaruh pelayanan dan kualitas produk terhadap kepuasan pelanggan Pada PT Aneka Tata Niaga. Melalui hasil yang telah dilakukan diperoleh $\mathrm{F}_{\text {hitung }}$ $(11,318)>F_{\text {tabel }}(3,08)$ dan nilai signifikansi $=0,000<0,05$ maka $\mathrm{H} 0$ ditolak dan Ha diterima.

\section{SIMPULAN}

1. Berdasarkan hasil penelitian ini menyatakan bahwa kualitas pelayanan (X1) berpengaruh signifikan secara parsial terhadap variabel kepuasan pelanggan (Y) pada PT Aneka Tata Niaga dan kualitas produk (X2) berpengaruh signifikan secara parsial terhadap variabel kepuasan pelanggan (Y) pada PT Aneka Tata Niaga.

2. Berdasarkan hasil penelitian diatas menyatakah bahwa dapat disimpulkan bahwa kualitas pelayanan (X1) dan kualitas produk (X2) bersama sama berpengaruh secara simultan terhadap kepuasan pelanggan $(\mathrm{Y})$ pada PT Aneka Tata Niaga.

\section{DAFTAR PUSTAKA}

Aswad, S., Realize, R., \& Wangdra, R. (2019). Pengaruh Harga Dan Kualitas Pelayanan Terhadap Kepuasan Konsumen Pengguna Air Bersih Masyarakat Kampung Air Batam Center. JIM UPB (Jurnal Ilmiah Manajemen Universitas Putera Batam), 6(2), 77. https://doi.org/10.33884/jimupb. v6i2.681 
Edwar M. Nur, C. I. (2018). Kualitas Jasa, Harga dan Pengaruhnya Terhadap Kepuasan Pelanggan, 2(1), 10-18.

Gunartik, \& Nainggolan, N. P. (2019). Pengaruh Kualitas Pelayanan Dan Fasilitas Terhadap Kepuasan Pengguna Perpustakaan (Di Politeknik Negeri Batam), 3(2), 29-39.

Isfahila, A., Fatimah, F., \& S, W. E. (2018). Pengaruh Harga, Desain, Serta Kualitas Produk Terhadap Kepuasan Konsumen. Jurnal Sains Manajemen Dan Bisnis Indonesia, 8(2), 211-227. https://doi.org/10.32528/jsmbi.v $8 \mathrm{i} 2.1790$

Meisara, gita vanya. (2019). Pengaruh Harga Dan Kualitas Produk Terhadap Kepuasan Pelanggan, $\quad 7(1), \quad$ 85-95. Retrieved from http://etd.uum.edu.my/4168/4/s8 10949_abstract.pdf

Rasyid, H. Al. (2017). Pengaruh Kualitas Layanan Dan Pemanfaatan Teknologi Terhadap Kepuasan Dan Loyalitas Pelanggan Go-Jek. Jurnal ECODEMICA, 1(2), 210-223. https://doi.org/10.31311/JECO. V1I2.2026

Sanusi, A. (2017). Metodologi
Penelitian Bisnis.

Sholeha, L., Djaja, S., \& Widodo, J. (2018). Pengaruh Kualitas Pelayanan Terhadap Kepuasan Pelanggan Di Ahass Sumber Jaya Maha Sakti Kecamatan Rogojampi Kabupaten Banyuwangi. JURNAL PENDIDIKAN EKONOMI: Jurnal Ilmiah Ilmu Pendidikan, Ilmu Ekonomi Dan Ilmu Sosial, 12(1), 15. https://doi.org/10.19184/jpe.v12i 1.6465

Sulaeman, A. (2018). Analisis Pengaruh Kualitas Pelayanan dan Produk Terhadap Kepuasan Pelanggan pada PT. Cakrawala Citramega. Jurnal KREATIF, 6(1), 125-145.

Widyastuti, T. (2017). Pengaruh Harga Dan Kualitas Produk Terhadap Kepuasan Pelanggan Tempe. Jurnal Ecodemica: Jurnal Ekonomi, Manajemen, Dan Bisnis, 1(2), 233-240. https://doi.org/10.31311/JECO. V1I2.2130 